DE DE GRUYTER

OPEN

DOI 10.2478/pesd-2014-0026

PESD, VOL. 8, no. 2, 2014

\title{
ANALYSIS OF THE DYNAMICS OF THE FOREST SURFACES IN THE COUNTY OF IAŞI BETWEEN 1990 AND 2012
}

\begin{abstract}
Alina Daniela Cojinovschi' ${ }^{1}$ Eugen Rusu ${ }^{1}$
Key words: forest surfaces, data quality check, Iaşi county, spatial and territorial autocorrelation effect

Abstract. The main dynamics that shaped the evolution of the forest surfaces between 1990 and 2012, in the county of Iaşi, are related to the legislative context and to the territorial reforms that affected the district limits. Analyzing these mechanisms in a geographical context shows that these trends are also related to the spatial frame. This study emphasizes that moderate negative coefficients of spatial and territorial autocorrelation can also describe these trends, suggesting that these evolutions are rather chaotic at local scale. This aspect makes us suspect that the loss of forest surfaces in each district is not only dependent on the economic, social and legislative context of the transition period, it is also subject to geographical factors. Analyzing these factors is the main intention of our study because they can provide us a better understanding of the extremely complicated frame of forest dynamics in the study area.
\end{abstract}

\section{Introduction}

Forest has always played an important role in human life, providing him with shelter, food (fruit, seeds and hunting resources), building material and tools. In Romania, the massive exploiting of forest is marked by the Treaty of Adrianople (1829) when the Romanian countries acquire their right to free navigation on the Danube and the Black Sea and the freedom of trade. Obtaining these privileges and population growth lead to increased farmland in the plains and plateaus areas by massive deforestation of broad-leaves forests, more accessible to coniferous forests in mountainous areas, their exploiting being more difficult and being conducting mainly to the top in the valleys. They then appear first problems caused by massive deforestation, a series of ordinances that aimed to protect forests (without much success though), followed by the reorganization of education and the emergence of

\footnotetext{
1 "Alexandru Ioan Cuza" University of Iași, Romania
} 
forest science (forestry) and the establishment in Bucharest of the "Progress Forest" (1886) and the publication of "Forest magazine". The first half of the twentieth century is marked by a series of memorable political events (the two world wars, the end of the monarchy, the beginning of the communist regime), each taking its toll on the stability and sustainability of Romanian forests by changing the forms of ownership and the emergence of land reforms that actually had catastrophic effects, warning signs being held by a number of foresters such as Marin Drăcea, Emil Pop, Gheorghe Ionescu-Şişeşti, N. R. Danilescu, and more.

In the contemporary period, the forest acquires multiple functions, are increasingly often the main topic of scientific papers ( Acad. C. Giurescu, Acad. V. Giurgiu, C. Chirită, etc.) but also the subject of numerous articles newspaper reports and political campaigns. Worldwide are set a number of international organizations and institutions aimed at the protection and sustainable development of forests ("is the kind of development that meets present needs without compromising future generations the chance to meet their own needs"-Commission World Environment and Development, 1987). In the Rio Conference (1992) appears ecological network Nature 2000, implemented in Romania between 20062008 , currently about $18 \%$ of the country is considered to be protected areas.

The main trends in the research today more often link the forests to climate change. In a paper called Plan 3-0. Mobilizing to save civilization, L. Brown claims that the main issues that should concern today are the demographic pressure, the increase of $\mathrm{CO} 2$ gas, exhaustion of natural resources, global warming and that "we cross verges that we can't see and death-lines we don't recognize ". That is why it is necessary to take some global measures (Dieter H.F. Schoene and Pierre Y. Bernier, 2012; N. La Porta et al., 2008) to stop the long term effect of human society over the forest. Between 1990 and 2005 were recorded some of the most droughty and hottest years in the human history, the lasts research claim that until 2100 global temperature will rise in Europe with $3^{\circ} \mathrm{C}$, even $4-5^{\circ} \mathrm{C}$ in the area of Black See (Lindner M., et al., 2010) and obviously affect the vitality of the forest, especially in the Southern part of Romania.

Another problem for the Romanian forest is the legislation (Giurescu, 1976; Giurgiu, 2000, 2010) and a poor collaboration between state institutions. The retrocession (a process that allows the return of forests nationalized under the communist regime back to the community owners or private ones, or to their descendants) that started at the end of ' 90 become a real challenge for Romanian state who lost almost $70 \%$ of the forest surfaces (Lawrence, A., 2009) and is now facing a highly fragmented estate of private property (Nijnik., M., et al., 2009), with an average holding of 0.9 ha.

In this context, a study related to the evolution of forest surfaces at local and intermediate level is more than necessary, both for a better academic understanding 
and for policy design support. This paper aims to identify the main trends that shaped the forest surfaces evolution between 1990 and 2012, based on data provided by reliable sources such as the NFA and TIFH, for the county of Iaşi. Using tools derived from the classical spatial analysis and cartographic depection of the dynamics, we identified the main chronological milestones in the evolution of the forests surfaces, at district scale. Subject to multiple political and legislative decisions ( 2 Forestry Codes published in the last 20 years) and territorial reforms (private forest districts), the dynamics of forest surfaces are sometimes hard to capture without a scrupulous data check methodology.

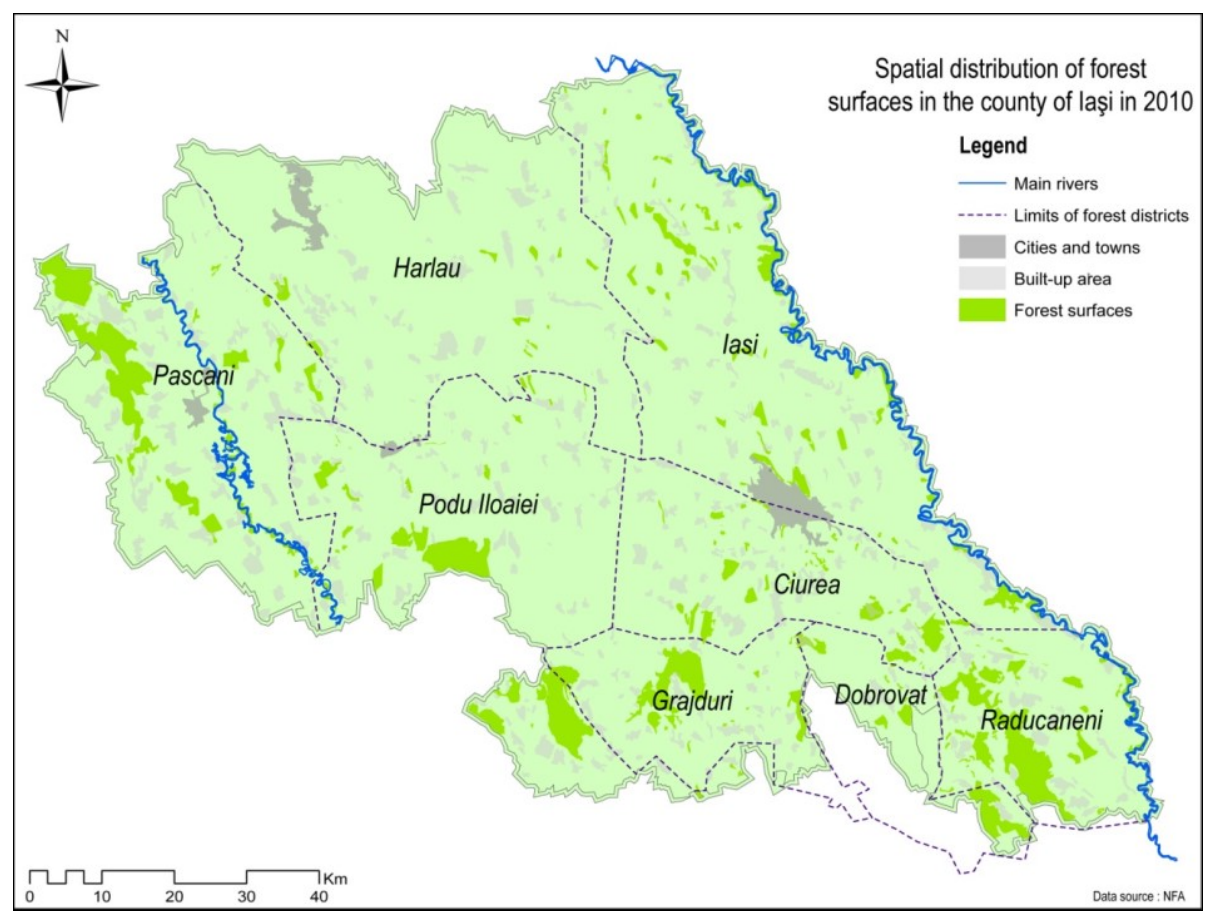

Fig. 1 Territorial distribution of forests in the County of Iaşi in 2010

Our main hypothesis states that the evolution's dynamics can be better understood when placed in a double geographical context - spatial and territorial. Our methodology is based on the construction of robust indicator of autocorrelation, which can be plotted in order to extract the trends. The cartographic analysis we propose serves as a secondary objective, explaining the dynamics at local scale (district), in various contexts (only 8 forest districts, a large amount of data, suspect values in the indicators or missing data). 


\section{Data and methods}

\subsection{Data Source}

The main data we used in this paper is provided by the NFA (National Forest Administration) and covers the situation of forests in the county of Iași for the period 1990-2012, excepting the year of 1999 when the Forestry Authority of Iași was dissolved. A secondary data source is TIFH (Territorial Inspectorate for Forests and Hunting). The information collected from this source covers the period between 2006 and 2012. A major shift in the legislation regarding the reporting methodology explains why we needed a secondary data provider in our research, some of the indicators being used in this paper becoming available only in the TIFH statistics. The National Statistical Institute provides data only at NUTS3 and NUTS2 level, a geographical scale not appropriate for our study. However, the statistic information provided by this institution was useful in order to compare stock data summarized from the first two data sources. Due to uncertainty in the quality of data, the EEA Corine Land Cover layers were not included in our analysis.

The data provided by NFA was not on electronic support and needed adjustments for use in GIS and statistical analysis. The lack of metadata was another problem encountered during our work. As a matter of fact, despite the good intentions of the RNP, they still lack a territorial vision in the forestry administration, their statistical database being more appropriate for economic audit intentions. This problem of the metadata absence involved a severe quality data check for outlier detection. A total amount of 2420 indicators and variables populated the database we created for this research. They can be grouped on 5 major categories, declined by the property status - public vs. private. The indicator named Public property is divided in forest in public property of state and forests in public property of the local administrative units. The indicator labeled Private property is composed by forests in private property of individuals and legal entities and forests in private property of local administrative units. To these four categories we added the total surfaces. Territorially, our information covers 8 forest districts in the county of Iaşi. The geographical division in the spatial administration of forests is another topic of discussion. The forest districts of Grajduri, Răducăneni and Dobrovăt have surfaces in the administration that belongs to the county of Vaslui. The district of Podu Iloaiei used to manage 25 hectares of forest in the Neamț county, between 1990 and 2004. However, the data we integrated in the research is spatially referred to districts covering only the NUTS3 of Iași.

\subsection{Data quality check}

The analysis of data for quality check involved an error tracking by summarized indicators - total surfaces of forests, coniferous forests, broad -leaved 
forests and other terrains. Generally, the error checking analysis revealed only minor mistakes, acceptable in our research. This type of errors (statistical outliers) is derived from misspecifications in the other terrains category. Less frequently, mistakes concerning the forest's total surface can be encountered. For example, in the case of the Răducăneni district a total amount of 160 hectares is missing from the reported surfaces (years of 1994-1996). These surfaces did not vanish, they were simply not taken into account as they were declared private property. This confused period of forests' restitution explains a large amount of the discrepancies within the data. The template of the statistical reporting of data was not constantly respected by the RNP, some of the data being excluded for incomprehensible reasons. When focusing on some particular years (e.g. the district of Podu Iloaiei in 1997) we observe significant differences between the total surface of other terrains and the sum of the indicators that compose this category (production, administration, constructions, afforestation etc.). What is inquisitive in this case is the fact that in the time series these mistakes are constantly revised and the errors are simply erased by adjusting other indicators. As a consequence of this data smoothing implemented by the NFA on the time-series, the total surfaces are always correct. As a first conclusion, taking into account the template of the reported information (variable in time), the issues observed for some particular years, the missing or not reported data, the quality data check was a necessary step in our research. In this moment, we estimate a rough ratio of $98 \%$ reliable statistical information in our data collection.

\subsection{Linking data to geometry}

The base map we use in this paper is provided the RNP. At origin it was a. dwg file for AutoCAD use and spatial visualization. The layers were converted and imported in ArcGIS and over-layed. A join field was created in our database, in order to allow us mapping the indicators. The base map is composed by several layers: the 8 districts present in the county of Iași, the built-up areas (rural and urban), the major hydrographic network and the forest surfaces managed by the NFA in 2010. A .kmz file was created using Google Earth (c)tm and it contains the most recent image of the forest cover for the Iași county. It serves for spatial data quality check; our intention was to observe the differences or concordance between the NFA geometry (2010) and the satellite images.

\subsection{Methods: statistical exploration and cartographic analysis}

The methodology we mobilized in this research is based on a quantitative approach that follows prudent steps: data quality check, spatial analysis and time series analysis. The major problem we faced in our analysis is the reduced number of districts (only 8); this issue is compensated by the quantity of indicators obtained by data collection. As we intend to observe the trends in the forest surface evolution between 1990 and 2012, we will use two different methods -the 
cartographic representation and analysis and the phase diagram instrument, the last one being extremely robust for trends identification. If the mapping process will emphasize the main dynamics of forest surfaces, at district level, the phase diagram will identify how these dynamics shift when changing the geographical scale. Basically, this phase diagram is a derived scatter-plot where the time is consubstantial to the data and the $\mathrm{X}$ and $\mathrm{Y}$ axis refer to the dynamics of two different spatial units.

\section{Results and discussions}

At the begining of the transition period (1990), the communist regime left a forestry fund of 6371 thousand hectares, most of it being located in the mountain and low-mountain area, more precisely in the North-West, Centre and North-East parts of Romania. That surface was the equivalent of $26.72 \%$ of the country's surface. The North-East Region (six NUTS3 - Bacău, Botoşani, Iaşi, Neamţ, Suceava and Vaslui) was cumulating in that moment about 1186.6 thousands hectares int the forestry fund, from which 1168 thousand hectares of forests. The three mountain counties of Suceava, Neamţ and Bacău were leaders in the regional top, with nearly $82 \%$ of the forest' surface. At regional scale the ratio between the species was almost equal - coniferous (581,5 thousand hectares) and broad-leaved species (586.5 thousand hectares).

At the same moment, the Forestry Authority of Iași was managing 8 forest districts (Paşcani, Dobrovăţ, Ciurea, Grajduri, Hârlău, Iaşi, Podu Iloaiei and Răducăneni); however, the spatial delineation of the forest surfaces was ignoring the county limits. Consequently, this authority was also managing forest surfaces in the neighbor counties of Vaslui (2927 ha, in 1990 with the districts of Dobrovăţ, Grajduri and Răducăneni) and Neamţ ( 25 ha managed by the district of Podu Iloaiei)._The statistical reports are related to this territorial frame of forest management, our intention was to explore the early 90' database and to order the information independently to the counties limits.

In 1990 the National Forest Administration of Iași managed a total fund of 96310 hectares (94083 hectares of forests). Excepting 124 ha (from which 91 ha of forests) managed by the Minstry of Defense and some industrial compartiments in the districts of Paşcani, these surfaces were exclusively in the property of the state. At county level, analyzing the density of forests, the opposition between the northern districts and the central-southern ones is easy to observe. Moreover, this opposition remains stable in time (1990-1998) the dynamics of this indicator being extremely low. Comparing the districts, one can identify some interesting disparities in the forest repartition. Thus, almost half of the forestry fund is located in three districts: Paşcani (14057 ha), Ciurea (15427 ha) and Podu Iloaiei (17044 ha), while two other districts present similar values but significantly lower - 
Dobrovăţ (9173 ha), Răducăneni (8813 ha). The last in this class is the district of Grajduri with a high-intermediate value of 11476 ha. All these 6 districts are in the category of spatial units with high densities of forest, on their territory.

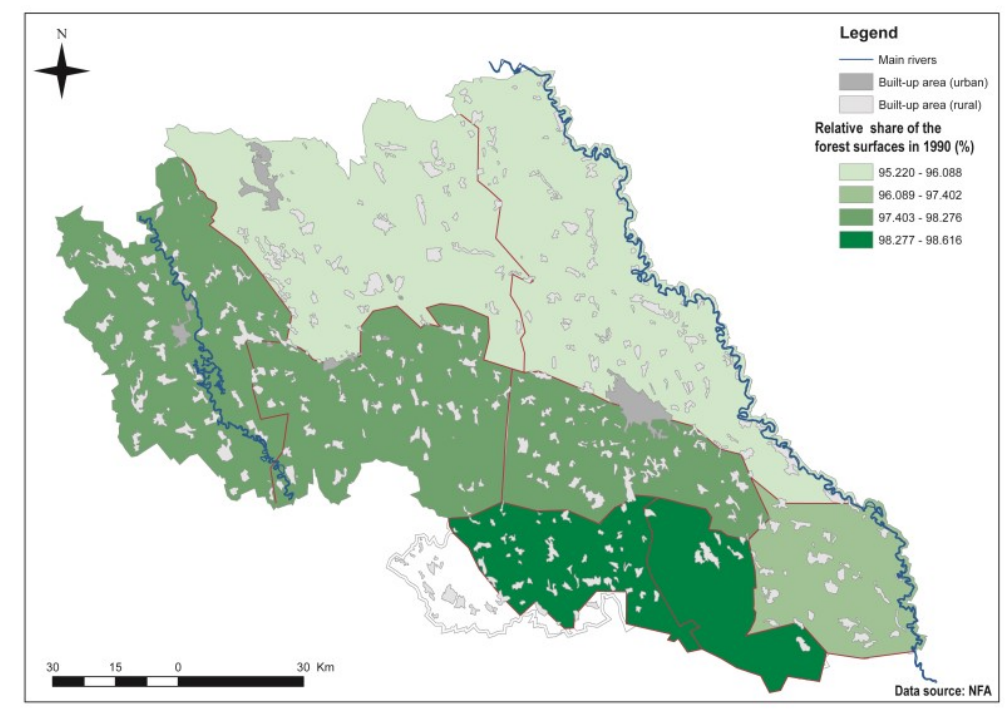

Fig. 2 Evolution of forest relative share at district level in 1990

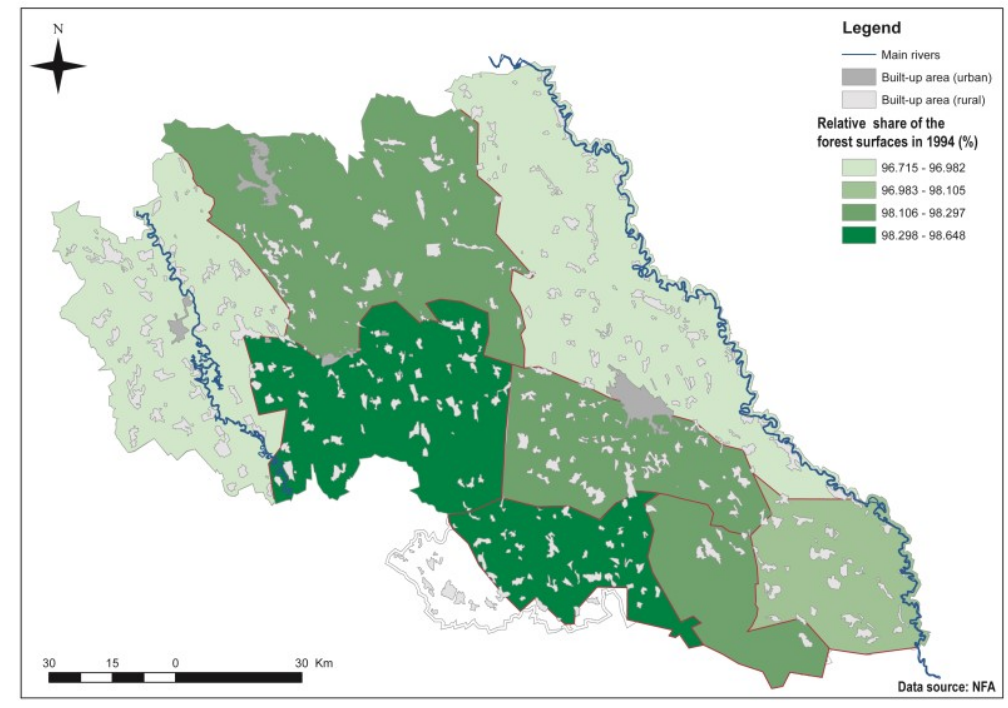

Fig. 3 Evolution of forest relative share at district level in 1994 


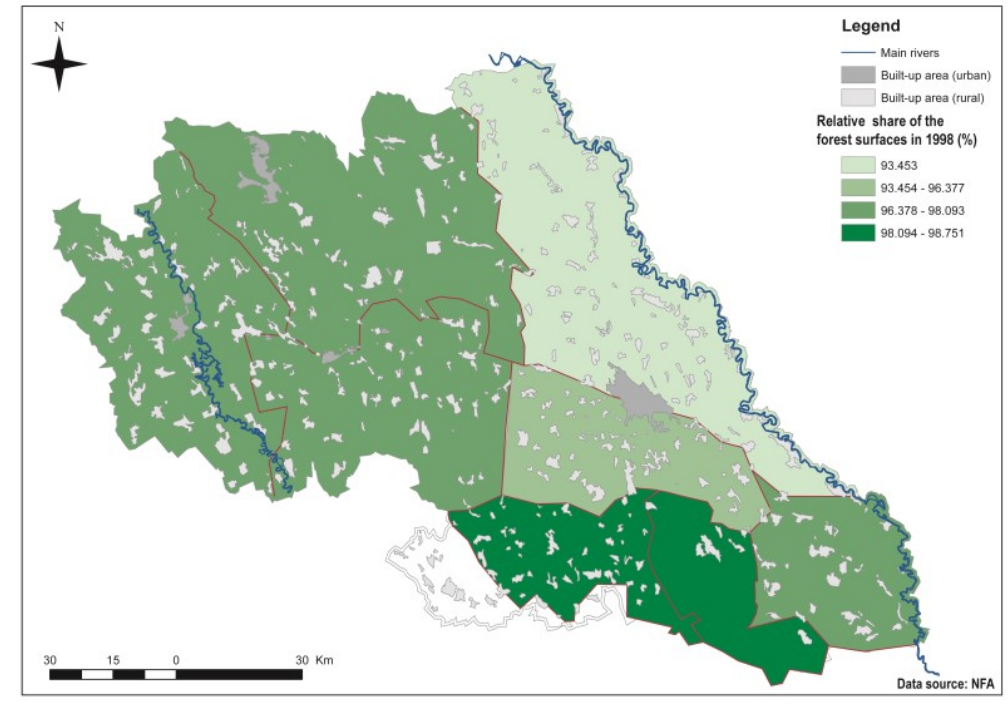

Fig. 4 Evolution of forest relative share at district level in 1998

The dynamics of the forest surfaces in the period of 1990-1998 is apparently stable, as the three maps (evolution of forest relative share in 1990, 1994 and 1998) illustrate. A point density map was used as tool to identify this overall general stability. The reduction of the surfaces covered by forest is almost unnoticeable in the northern part of the county (districts of Iași, Hîrlău and Pașcani), while in the southern area is more visible, especially in the districts of Dobrovăț and Răducăneni. This situation is not explained by the quality of data, active processes of deforestation being perceptible for this period of time.

In relative terms, some of the districts loosed almost $2 \%$ of the forest managed by the RNP; it is the case of the district of Podu Iloaiei. Only one district registered an increase of forest surfaces, it is the case for Grajduri. The dynamics become more accelerated after the year 2000. For the next 12 years, the map shows a reduction of the forest surfaces that reaches almost $30 \%$ in the district of Podu Iloaiei. This negative trend is also visible for other spatial units, but less intensive. In the same time, the districts situated in the Valley of Prut river shows the most reduced deforestation trends (Iași and Răducăneni). 


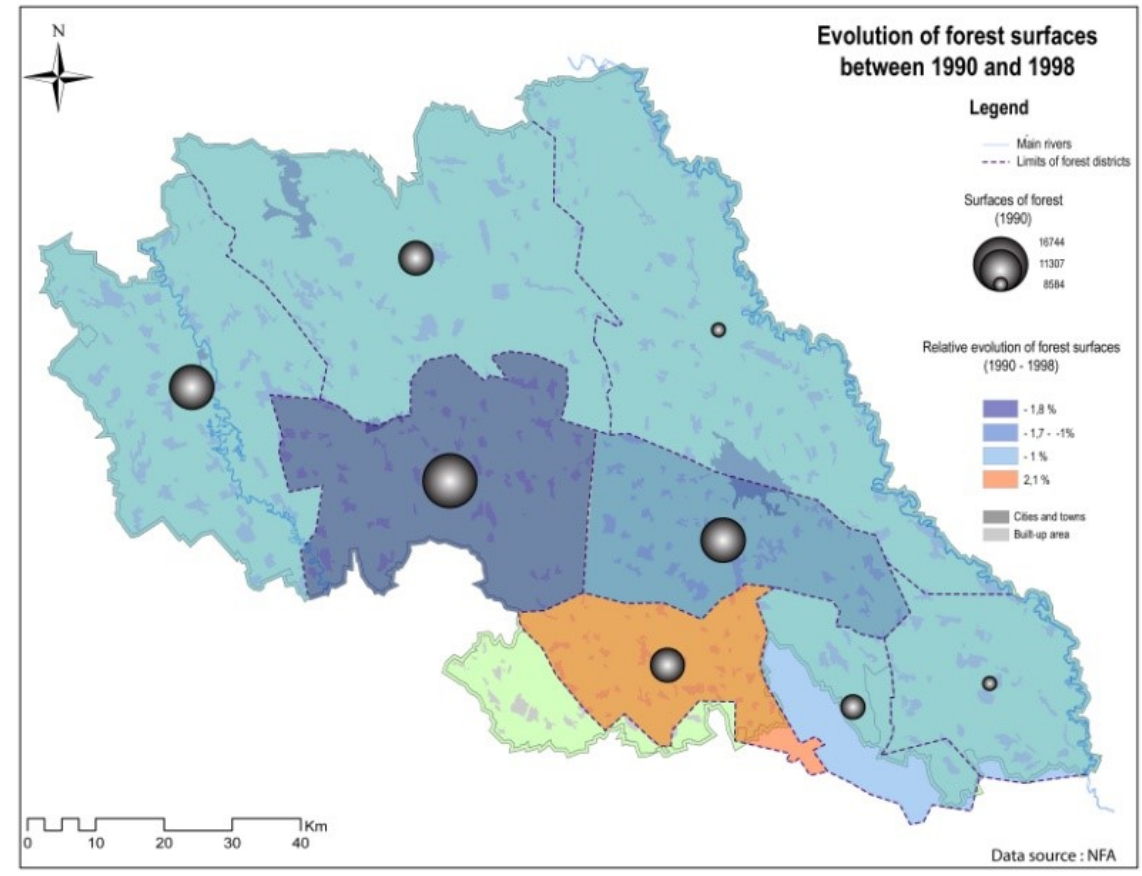

Fig. 5 Evolution of forest surfaces between 1990 and 1998

The trends we observe behave differently when analyzed in a spatial and territorial context. The method we propose will identify these trends using tools derived from the spatial analysis. Two particular instruments will be used in this approach: a chrono-variogram of spatial and territorial auto-correlation and the phase diagram using data for neighbor districts. In order to explore how the spatial and territorial context interfere with the dynamics of the forest surfaces, the relative evolutions of the indicators will be weighted with two binary matrices, one describing the neighborhood relations and one the territorial belonging.

Our main hypothesis states that there is a spatial and territorial effect in the evolution of forest surfaces, at district level. This effect can be measured by an indicator of spatial auto-correlation that was calculated for the period between 1990 and 2012. The first step in the implementation of this method is the construction of spatial weighted matrix of relations between the districts. We have made an option for a binary contiguity based matrix. With only eight districts to analyze, other methods proposed in the literature (inverse distance weight, knearest neighbors and fixed distance band) are not appropriated taking into account the small number of spatial units. The second step consisted in the preparation of a 
dissimilarity matrix for two indicators - surfaces of forest at district level (absolute values) and their relative evolution between 1991 and 2012. The analysis was iterated for all the available years, excepting 1999, 2003, 2004 and 2005 (due to the missing of data) and the results synthesized in a correlogram that presents two

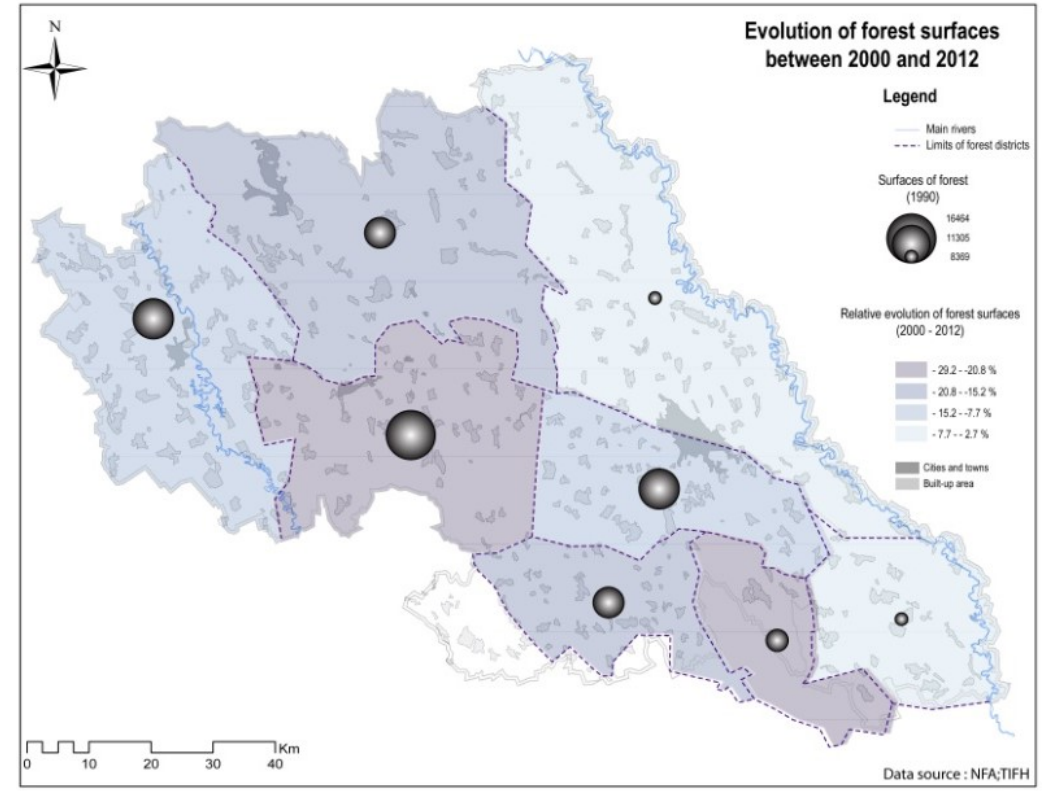

Fig. 6 Evolution of forest surfaces between 2000 and 2012

Tab. 1 Dissimilarity matrix for the relative evolution of forest (2012)

\begin{tabular}{|c|c|c|c|c|c|c|c|c|c|c|}
\hline Dissim ij & & CRT & 1 & 2 & 3 & 4 & 5 & 6 & 7 & 8 \\
\hline & & su & PASCANII & DOBFOVAT & CIUREA & GRAI DURI & HARLAU & IASI & PODUILOAIE & RADUCANENN \\
\hline CRT & SU & $Y 2012$ & \begin{tabular}{|l|}
91.93 \\
\end{tabular} & \begin{tabular}{|l|}
79.10 \\
\end{tabular} & \begin{tabular}{|r|}
83.58 \\
\end{tabular} & \begin{tabular}{|l|}
81.56 \\
\end{tabular} & \begin{tabular}{|l|}
84.24 \\
\end{tabular} & 95.47 & \begin{tabular}{|l|}
69.61 \\
\end{tabular} & \begin{tabular}{|l|}
96.17 \\
\end{tabular} \\
\hline 1 & PASCANII & 91.93 & 0.000 & 12.832 & 8.345 & 10.368 & 7.692 & 3.545 & 22.315 & 4.239 \\
\hline 2 & DOBROVAT & 79.10 & 12.832 & 0.000 & 4.487 & 2.464 & 5.140 & 16.377 & 9.483 & 17.072 \\
\hline 3 & CIUREA & 83.58 & 8.345 & 4.487 & 0.000 & 2.023 & 0.653 & 11.890 & 13.970 & 12.584 \\
\hline 4 & GRAI DURI & 81.56 & 10.368 & 2.464 & 2.023 & 0.000 & 2.676 & 13.913 & 11.947 & 14.607 \\
\hline 5 & HARLAU & 84.24 & 7.692 & 5.140 & 0.653 & 2.676 & 0.000 & 11.237 & 14.623 & 11.931 \\
\hline 6 & IASI & 95.47 & 3.545 & 16.377 & 11.890 & 13.913 & 11.237 & 0.000 & 25.860 & 0.695 \\
\hline 7 & PODUILOAIE & 69.61 & 22.315 & 9.483 & 13.970 & 11.947 & 14.623 & 25.860 & 0.000 & 26.554 \\
\hline 8 & RADUC ANEN & 96.17 & 4.239 & 17.072 & 12.584 & 14.607 & 11.931 & 0.695 & 26.554 & 0.000 \\
\hline
\end{tabular}

distinct trends. The evolution of forest surfaces as absolute values has a constant trend of negative spatial auto-correlation (maximum: -0.31 and minimum: -0.14). This trend suggests that the evolutions observed are independent to the spatial 
context, indicating the presence of a significant heterogeneity on the map. Locally, each district presents a trend of absolute evolution that differs from the neighbors.

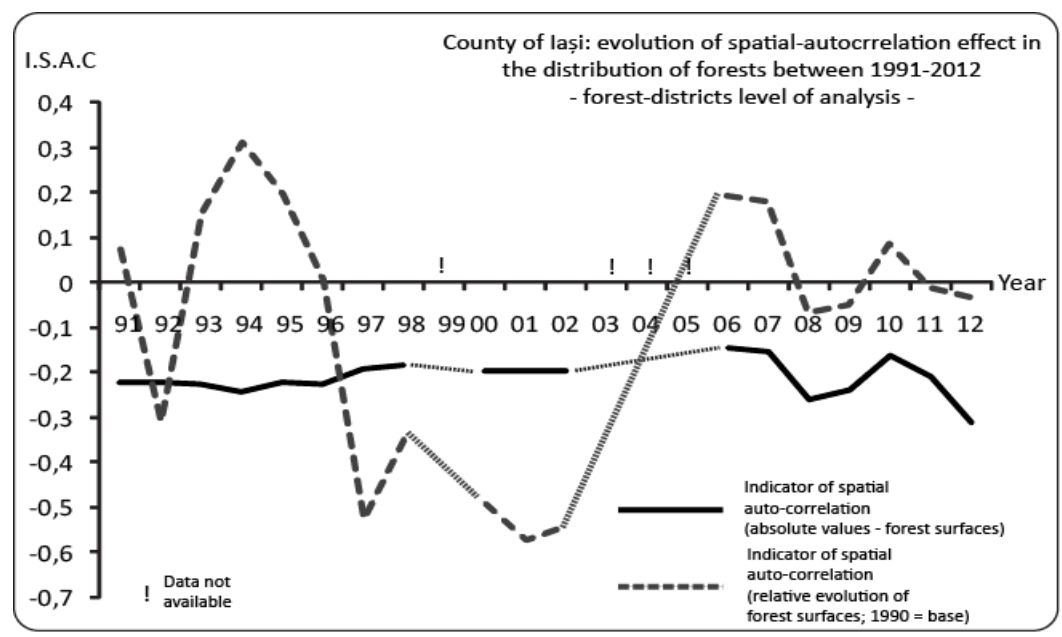

Fig. 7 Evolution of SAC effect between 1991 and 2012

Contrasting to the absolute evolution of the forest surfaces, the relative trends are marked by positive spatial auto-correlation. The graphic shows that the relative reduction or extension of forest surfaces was highly dependent on the spatial context for years like 1993, 1994, 1995, 2006 and 2007. The local trends become heterogeneous after 1996, if we analyze the values of the indicator, culminating with a strong negative coefficient in 2001(-0.57). The construction of the autocorrelation coefficient is based on the aggregated variance of the dissimilarities between districts, in a double context - neighborhood and non-contiguity.

$$
\text { I.S.A.C }=1-\frac{\sum \frac{D i j}{n} ; r=1}{\sum \frac{D i j}{n} ; r=0}
$$

I.S.A.C. $=$ indicator of spatial autocorrelation

Dij $=$ absolute dissimilarity between any two $(\mathrm{i}, \mathrm{j})$ districts, for the indicators we analyzed - value of the forest surfaces and relative evolution of forest surfaces.

$\mathrm{n}=$ number of spatial units

$\mathrm{r}=$ the value of the spatial relation between any two districts ( 1 if neighbors, else 0 ) 


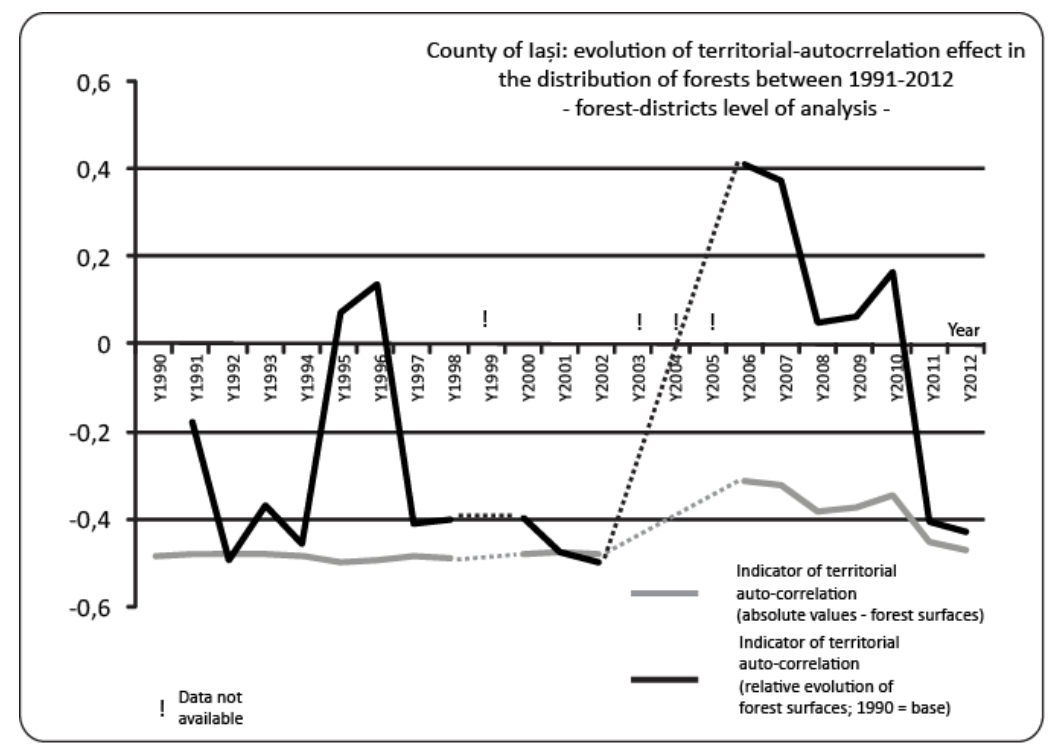

Fig.8 Evolution of TAC effect between 1991 and 2012

The value of the I.S.A.C could be interpreted similarly to the Pearson' coefficient of statistical correlation. If the value is closed to 1 , we assist to positive spatial autocorrelation. When the value is closed to -1 , one will deal with negative spatial correlation. When I.S.A.C. is closed to 0 , we cannot detect the role played by space in the distribution of an indicator.

The same method of analysis was applied choosing a different context for the weighted values of the dissimilarities between forest districts, the territorial belonging. The eight districts were divided in two regions - the South Region (Răducăneni, Dobrovăț, Ciurea and Grajduri) and the North Region (Pașcani, Hârlău, Podu Iloaiei and Iași) and a new matrix was built (a binary table containing values of 0 and 1). Analyzing the maps, we suspected that this effect of territorial belonging could also explain the trends of evolution of the forest surfaces, either in absolute or relative terms.

After the iteration of the method we have obtained a graph that depicts the evolution of the coefficient of territorial autocorrelation between 1991 and 2012. The coefficient presents a strong and stable effect of negative territorial autocorrelation for the evolution of forest surfaces (absolute values). This should be interpreted as regional heterogeneity - any pair of districts belonging to the South or North region shows divergent trends of evolution. Contrary, in the case of the relative indicator, we observe a cyclical trend with two picks of positive 
territorial autocorrelation (1996 and 2006). In this case, belonging to one region (South or North of the county) will partially explain the relative trends of evolution for the forest surfaces.

The synthesis of the analysis allowed us to identify some atypical years in the evolution of the forest surfaces, for the county of Iași, at district level. If the role played by the spatial and territorial context is stable and predictable, for the case of the absolute values, shifts will occur in the trends when analyzing the relative evolutions. Two years are particularly interesting - 1997 and 2006. For both years, the values of the SAC and TAC coefficients shift the sign, meaning that the influence played by the geographical contexts (spatial and territorial belonging) was reversed. Without systematically investigating the trends using the method we proposed, detecting these years would have been difficult, needing map analysis for 18 years of forest evolution.

Tab. 2 Outlier values of SAC and TAC in chronological context

\begin{tabular}{|c|c|c|c|c|}
\hline & $\begin{array}{l}\text { SAC_VAL_ } \\
\text { ABS }\end{array}$ & $\mid \begin{array}{l}\text { SAC_VAL } \\
\text { REL }\end{array}$ & $\begin{array}{l}\text { TAC_VAL } \\
\text { ABS }\end{array}$ & $\begin{array}{l}\text { TAC_VAL } \\
\text { REL }\end{array}$ \\
\hline Y1990 & -0.224 & & -0.486 & \\
\hline Y1991 & -0.223 & 0.074 & -0.484 & -0.179 \\
\hline Y1992 & -0.220 & -0.311 & -0.483 & -0.499 \\
\hline Y1993 & -0.225 & 0.153 & -0.483 & -0.371 \\
\hline Y1994 & -0.243 & 0.310 & -0.489 & -0.458 \\
\hline Y1995 & -0.222 & 0.195 & -0.501 & 0.070 \\
\hline Y1996 & -0.225 & 0.004 & -0.496 & 0.135 \\
\hline Y1997 & -0.191 & -0.528 & -0.488 & -0.415 \\
\hline Y1998 & -0.184 & -0.349 & -0.492 & -0.402 \\
\hline Y2000 & -0.196 & -0.496 & -0.482 & -0.397 \\
\hline Y2001 & -0.196 & -0.576 & -0.480 & -0.479 \\
\hline Y2002 & -0.196 & -0.546 & -0.481 & -0.501 \\
\hline Y2006 & -0.145 & 0.192 & -0.313 & 0.409 \\
\hline Y2007 & -0.153 & 0.177 & -0.321 & 0.372 \\
\hline Y2008 & -0.258 & -0.071 & -0.385 & 0.049 \\
\hline Y2009 & -0.240 & -0.052 & -0.377 & 0.061 \\
\hline$Y 2010$ & -0.162 & 0.086 & -0.347 & 0.161 \\
\hline Y2011 & -0.207 & -0.012 & -0.452 & -0.408 \\
\hline Y2012 & -0.310 & -0.036 & -0.474 & -0.434 \\
\hline
\end{tabular}




\section{Conclusions}

In the almost chaotic context of the forest dynamics that affects the county of Iaşi, between 1990 and 2012, one can observe that these surfaces are decaying according to a geographical pattern that can be measured using the spatial and territorial autocorrelation coefficients. This decline is marked by heterogeneity, both at local and zonal scale (North vs. South of the county). The explanation of this heterogeneity should be linked to the legislative retrocession of forest surfaces, a legislative mechanism with different rhythms at district and LAU2 (local administrative unit - UAT) level. In this logic, the most affected districts are Paşcani, Grajduri and Podu Iloaiei. The chronological evolutions of the coefficients we propose indicate that there are some key years $(1992,1997$ and 2006) that deserve a special focus in the analysis of the forest trends. If in 1992 the retrocession process just began to show its effects, in 1997 the legislative frame is changed by a new forestry code. In 2006 we assist to a massive change in the providing of official data related to the forest surfaces. The data from TIFH allows us to perform a more detailed analysis of the 2006-2012 period, introducing new actors involved in the management of the private surfaces. In the context of our study, the main conclusion states that despite the negative trends of evolution are not dramatic and that the geographical research should focus more on the administrative and legislative frame that explains how these trends function.

\section{Refrences}

Behrens, H.: Eastern Europe struggles with forest management challenges, Journal of soil and water Conservation number 5, volume 61, 2006

Bernier, P., Schoene, D.: Adapting forest and their management to climate change - an overview, Unasylva, volume 60, 2009

Brown, L.: Plan 3-0. Mobilizing to save civilization, Technical Press, Bucharest, 2008

Burley, J., Evans, J., Youngquist, J. A.: Encyclopedia of forest sciences, Elsevier Academic Press, 2004

Chiriță, C., Doniță, N., Ivănescu, D., Lupe, I., Milescu, I., Stănescu, V., and Vlad, I.: Romanian Forests, Academy Press, Bucharest, 1981

Dutcă, I., Abrudan, I. V.: Estimation of forest land-cover in Romania, between 19902006, Bulletin of the Transylvania University of Brașov , volume 3, 2010

Giurescu, C. C.: The history of Romanian forest from oldest time until today, Cereș Press, Bucharest, 1976

Giurgiu, V.: Evolution of Romanian forest structure depending on the nature of propriety, Forest Magazine number 1, 2000

Giurgiu, V.: Forests and environment changes, Academy Press, Bucharest, 2005

Giurgiu, V.: Considerations on Romanian forest found, Forest Magazine number 2, 2010

Giurgiu, V.: Forests and climate change, Forest Magazine number 3, 2010 
Helms, J. A.: The dictionary of Forestry, CAB International and the Society of American Foresters, 1998

Ioras, F.: Trends in Romanian biodiversity conservation policy, Biodiversity and Conservation, Kluwer Academic Publishers, pp 9-23, 2003

La Porta, N. et al.: Forest pathogens with higher damage potential due to climate change in Europe, Canadian Journal of Plant Pathology, 2008

Lawrence, A.: Forestry in transition: Imperial legacy and negotiated expertise in Romania and Poland, Forest Policy and Economics 11, pp 429-436, 2009

Lindner, $M$ et al.: Climate change impacts, adaptive capacity and vulnerability of European forest ecosystems, Forest Ecology and Management 259, Elsevier Press, pp 698-709, 2010

Maracchi, G., Sirotenko, O., Bindi, M.: Impacts of present and future climate variability on agriculture and forestry in the temperate regions: Europe, Climatic Change 70, Springer Press, pp 117-135, 2005

Nijnik, M., Nijnik, A., Bizikova, L.: Analyzing the development of small scale Forestry in Central and Eastern Europe, Small Scale Forestry, pp 159-174, 2009

Rusu, E.: Current trends of development of forests areas to protect soil and water at global and regional level, Dimitrie Cantemir Geographic seminar, Iași, 2011

Rusu, E.: Forest geography, Univ. Al. I. Cuza Press, Iași, 2012

Schoene, D. H. F., Bernier, P. Y.: Adapting forestry and forest to climate change: A challenge to change the paradigm, Forest Policy and Economics 24, pp 12-19, 2012

Ursu, A., Stoleriu, C., Sfica, C., Roșca, L.: Corine Land Cover Nomenclature adaptation to land use change specific of Romania, Technical Geography, pp163-198, 2006

Veen, P. et al.: Virgin forests in Romania and Bulgaria: results of two national inventory projects and their implications for protection, Biodiversity Conservation, Springer Press, pp 1805-1819, 2010

Vilen, T. et al.: Reconstructed forest age structure in Europe 1950-2010, Forest Ecology and Management 286, Elsevier Press, pp 203-218, 2012 